\title{
Importance of Dietary Calcium in the Definition of Hypercalciuria
}

\author{
M. PEACOCK,* M.B., CH.B.; A. HODGKINSON,* D.SC., F.R.I.C. ; B. E. C. NORDIN,* M.D., PH.D., M.R.C.P.
}

Brit. med. F.. 1967, 3, 469-471

The relation between a high urinary calcium and renal stone disease was first noted by Flocks in 1939, but the recognition of "idiopathic hypercalciuria" as an entity in its own right dates from 1953, when the condition was described by Albright, Henneman, Benedict, and Forbes. These workers defined a syndrome in which a high urinary calcium was associated with normocalcaemia, a tendency to hypophosphataemia, and renal stone formation, and this syndrome has since been recognized by many other workers in the field (Henneman, Benedict, Forbes, and Dudley, 1958 ; Harrison, 1959 ; Litin, Diessner, and Keating, 1961 ; Parfitt, Higgins, Nassim, Collins, and Hilb, 1964 ; Edwards and Hodgkinson, 1965).

The cause of the high urinary calcium has never been established. The original workers suggested that it was a renal tubular disorder possibly associated with an ascending pyelonephritis (Albright et al., 1953), but this has never been confirmed. Other workers have subsequently observed a reduced faecal excretion of calcium in idiopathic hypercalciuria (Henneman et al., 1958 ; Harrison, 1959; Jackson and Dancaster, 1959 ; Hodgkinson, 1961). Whether this is the cause or the result of the condition is unknown, but Jackson and Dancaster (1959) suggested that the hyperabsorption was secondary to the hypercalciuria. Attempts to lower the urinary calcium by restricting calcium intake have been successful in some cases (Hennemann et al., 1958 ; Harrison, 1959 ; Gill and Bartter, 1961) but not in others (Jackson and Dancaster, 1959 ; Edwards and Hodgkinson, 1965). This discrepancy may signify that some of the patients studied have tubular hypercalciuria or that the restriction of dietary calcium has been inadequate. Dent and Watson (1965), for instance, described the case of a man with hypercalciuria whose urinary calcium was finally reduced to normal when he was instructed to drink distilled water in addition to having a very strict low-calcium diet.

In studying this problem further we have encountered difficulty in defining exactly what is meant by hypercalciuria. Though the definition of Hodgkinson and Pyrah (1958)-a urinary calcium over $250 \mathrm{mg}$. in females and $300 \mathrm{mg}$. in males-has been widely adopted and proved useful in practice, we have seen many patients whose urinary calcium on a free diet varies substantially from one day to another. Such patients would be defined as "hypercalciuric" on one occasion and as "normocalciuric" on another. We have therefore found it necessary to examine in more detail the relation between dietary and urinary calcium in an attempt to define more rigorousiy what is meant by hypercalciuria and to understand its nature.

The present paper deals with the relation between dietary and urinary calcium in normal and stone-forming subjects and presents evidence to suggest that hyperabsorption is more likely to be the cause than the result of idiopathic hypercalciuria.

\section{Clinical Material and Methods}

Stone-forming Patients. - The patients consisted of 31 idiopathic male stone-formers and 21 idiopathic female stoneformers, most of them having been "hypercalciuric" at one

- Medical Research Council Mineral Metabolism Unit, the General Infirmary, Leeds 1 . time or another according to the definition given above. They were admitted to a metabolic ward and studied on two known calcium intakes: a low intake of $2-5 \mathrm{mg} . / \mathrm{kg}$. $/$ day and a high intake of $15-20 \mathrm{mg} . / \mathrm{kg}$./day. The duration of study on each intake was variable, but was not less than five days. Urine was collected 24-hourly for calcium estimation, and the calcium excretion was expressed as the average of the last three days on a particular regimen.

Controls.-These were of two kinds: observations of our own and data collected from the literature. Our own nonstone cases comprise all the subjects studied by us at two calcium intakes who had no disease involving or affecting calcium metabolism other than simple ageing. There are 13 males in this category and 21 females. In addition, we have collected from the literature data on 31 normal male adults in whom urinary calcium data were available at two intake levels (Steggerda and Mitchell, 1941; Malm, 1958; Jackson and Dancaster, 1959 ; Clarkson, McDonald, and de Wardener, 1966). Our own control data fell within the same range as the normal data extracted from the literature.

Diets.-The patients were first studied on a low-calcium diet. This was followed by a high-calcium diet which consisted of the previous low-calcium diet supplemented with milk.

Biochemical Methods.-Various biochemical methods were used for the measurement of urinary calcium since the data were collected over a period of 12 years. The main methods were oxalate precipitation followed by permanganate titration, flame photometry by means of the Eppendorf flame photometer, or colorimetry with murexide or cresolphthalein complexone (Technicon Instruments Ltd. Method N 3). There is satisfactory agreement between urine calcium values obtained by these four methods.

\section{Results}

The relation between urinary and dietary calcium in the male subjects is shown in Fig. 1. The shaded area represents the normal range as established by us previously from observations in the literature (Nordin and Smith, 1965). It is apparent that in the great majority of stone-formers the urinary calcium on

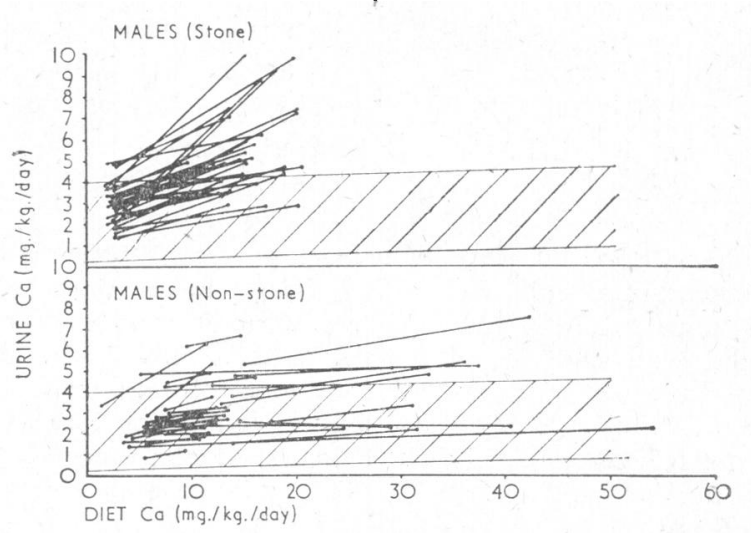

FIG. 1.-Relation between urinary and dietary calcium in male stone-formers (top) and non-stone-formers (below). The shaded area represents the approximate normal range. 
a low-calcium diet falls within the normal range. However, when the dietary intake is raised, urinary calcium rises steeply in most cases until at the higher intakes it is generally above or at the upper limit of the normal range. By contrast, the great majority of the male controls fall within or only slightly above the normal range, and, in particular, do not show the steep slope of urinary on dietary calcium which is a feature of the stone-formers.

The corresponding data for females are shown in Fig. 2. In the women there is very much less difference between stoneformers and controls than in the men. A few stone-forming

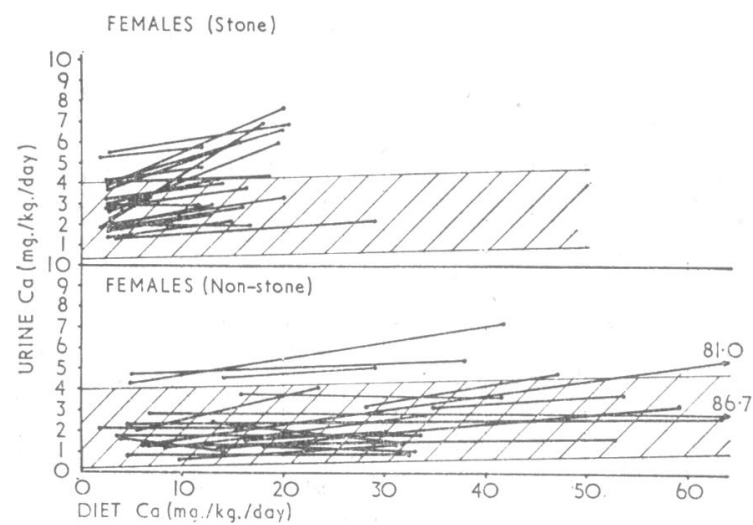

FIG. 2.-Relation between urinary and dietary calcium in female stone-formers (top) and non-stone-formers (below). The shaded area represents the approximate normal range.

cases lie above the suggested normal range, but the same is true of three of the controls. Some of the stone-forming cases have rather steeper slopes of urinary on dietary calcium than are seen in the control series, but most are within the normal range in this respect.

These data can also be analysed in other ways. Firstly, the relation between urinary and dietary calcium can be expressed as a slope which denotes the change in urinary calcium for each unit change in dietary calcium. Secondly, this slope of urinary calcium on diet can be extrapolated back to a theoretical zero intake and the result expressed as the intercept of the slope on the urinary calcium axis. The data shown in Figs. 1 and 2 are expressed in these two ways in Figs. 3 and 4 and in the Table.

Relation of Urinary to Dietary Calcium in Stone-forming and Nonstone-forming Individuals

\begin{tabular}{|c|c|c|c|c|c|c|c|c|}
\hline & \multicolumn{3}{|c|}{ Non-stone Cases } & \multicolumn{3}{|c|}{ Stone Cases } & \multirow[b]{2}{*}{$t$} & \multirow[b]{2}{*}{$r$} \\
\hline & $\left|\begin{array}{c}\text { No. } \\
\text { of } \\
\text { Cases }\end{array}\right|$ & Mean & S.E. & $\mid \begin{array}{c}\text { No. } \\
\text { of } \\
\text { Cases }\end{array}$ & Mean & S.E. & & \\
\hline & \multicolumn{8}{|c|}{ Mean regression coefficients of urinary on dietary calcium } \\
\hline \multirow[t]{2}{*}{$\begin{array}{l}\text { Males } \\
\text { Females }\end{array}$} & $\begin{array}{l}44 \\
21\end{array}$ & $\begin{array}{l}0.074 \\
0.029\end{array}$ & $\begin{array}{l}0.012 \\
0.008\end{array}$ & $\begin{array}{l}31 \\
21\end{array}$ & $\begin{array}{l}0.199 \\
0.105\end{array}$ & $\begin{array}{l}0.020 \\
0.019\end{array}$ & $\begin{array}{l}5 \cdot 4 \\
3 \cdot 8\end{array}$ & $\begin{array}{l}<0.001 \\
<0.001\end{array}$ \\
\hline & \multicolumn{8}{|c|}{ Mean values of theoretical minimal urinary calcium (mg.!kg./day) } \\
\hline $\begin{array}{l}\text { Males } \\
\text { Females }\end{array}$ & $\begin{array}{l}44 \\
21\end{array}$ & $\begin{array}{l}2.31 \\
1.95\end{array}$ & $\begin{array}{l}0.19 \\
0.28\end{array}$ & $\begin{array}{l}31 \\
21\end{array}$ & $\begin{array}{l}2.37 \\
2.53\end{array}$ & $\begin{array}{l}0 \cdot 16 \\
0.22\end{array}$ & $\begin{array}{l}0.24 \\
1.66\end{array}$ & $\begin{array}{l}>0.1 \\
>0.1\end{array}$ \\
\hline
\end{tabular}

Fig. 3 shows the slope of urinary on dietary calcium in the stone-forming and non-stone-forming males and females. It is apparent that this slope has a gradient of less than 0.1 in the great majority of control males (mean 0.074) and of more than 0.1 in nearly all the stone-forming males (mean 0.199). This difference is highly significant (see Table). In the females the mean slope in the stone-formers is 0.105 and in the controls 0.029. This difference is also highly significant.

The theoretical urinary calcium values at zero calcium intake are shown in Fig. 4. The mean in the male non-stone-forming cases is 2.31 and in the stone-formers $2.37 \mathrm{mg} . / \mathrm{kg}$./day. In the females the corresponding values are 1.95 and 2.53 mg./kg./day. These differences are not significant (see Table).

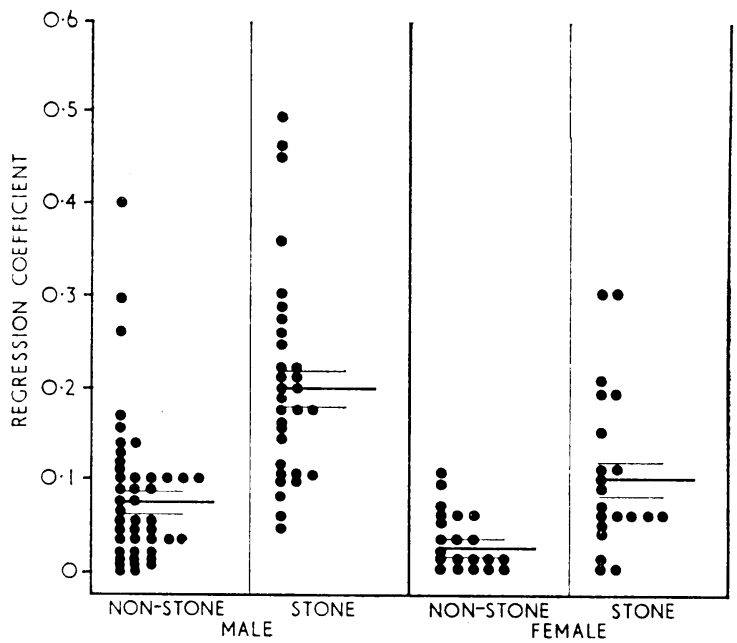

FIG. 3.-Regression coefficients of urinary on dietary calcium in male and female stone-formers compared with non-stoneforming individuals. The horizontal bars represent the means \pm one standard error.

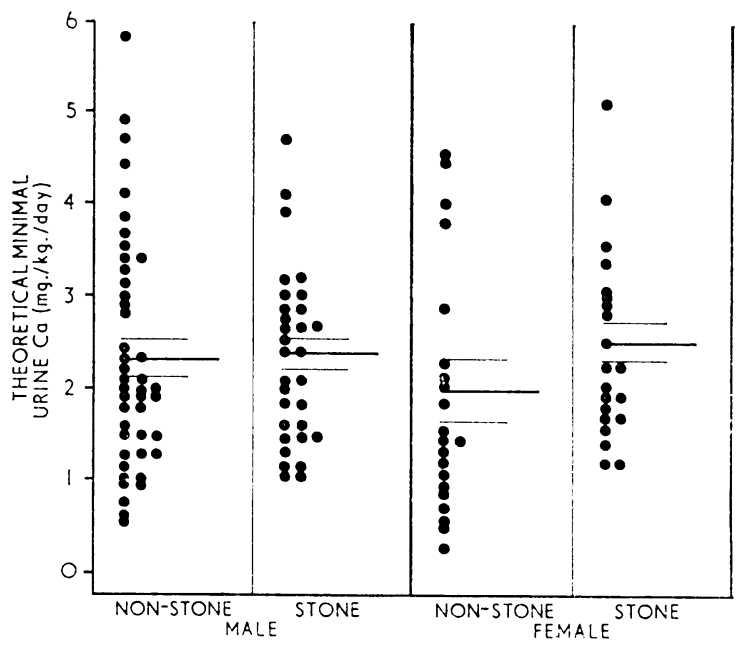

FIG. 4.-Theoretical minimal urinary calcium at zero calcium intake in male and female stone-forming and nonstone-forming individuals. The horizontal bars represent the means tone standard error.

\section{Discussion}

Our data show that hypercalciuria should only be defined in relation to dietary calcium intake. Though the definition of hypercalciuria proposed by Hodgkinson and Pyrah (1958) has been and remains a useful guide, the fact that urinary and dietary calcium are closely related in stone-forming subjects indicates the need to define the dietary intake whenever the urinary calcium is examined in detail. Measurement of urinary calcium at two levels of intake enables patients to be classified into three different categories. Firstly, those in whom urinary calcium is high on a high intake but falls into the normal range on a low intake; these probably represent the majority of the male cases of so-called "idiopathic hypercalciuria." Secondly, those in whom urinary calcium is high on a high intake but remains high on a low intake; this is the general picture with sustained hypercalcaemia, but in the absence of hypercalcaemia probably denotes reduced tubular reabsorption of calcium. Thirdly, those patients whose urinary calcium falls within the normal range at high- and low-calcium intakes and who from this point of view are entirely normal. 
We find that the majority of cases of idiopathic hypercalciuria, particularly the males, fall into the first category. Their urinary calcium at very low intakes is normal-that is, less than $4 \mathrm{mg}$. $/ \mathrm{kg}$./day-but it rises more steeply than normal as intake is raised, and therefore tends to be high on the average dietary calcium of this country (about $20 \mathrm{mg} . / \mathrm{kg} . /$ day). This close relation between dietary and urinary calcium suggests, but does not prove, that the hypercalciuria is absorptive in origin as Caniggia, Gennari, and Cesari (1965) believe. It is possible to conceive of a renal "leak" which operates only at high intakes of calcium, but this seems to us an improbable explanation of our results.

In women the picture is much the same, though only a minority of the female stone-formers (6 out of 21) have a slope of urinary on dietary calcium above the upper limit of non-stone controls. The difference between the mean slopes is highly significant, whereas the theoretical urine calcium at zero intake does not differ as between the two groups.

It would be of the greatest interest to know whether the hypercalciuria of renal stone disease has the same basis as the hypercalciuria seen in a proportion of apparently normal individuals. It has repeatedly been noted that the urinary

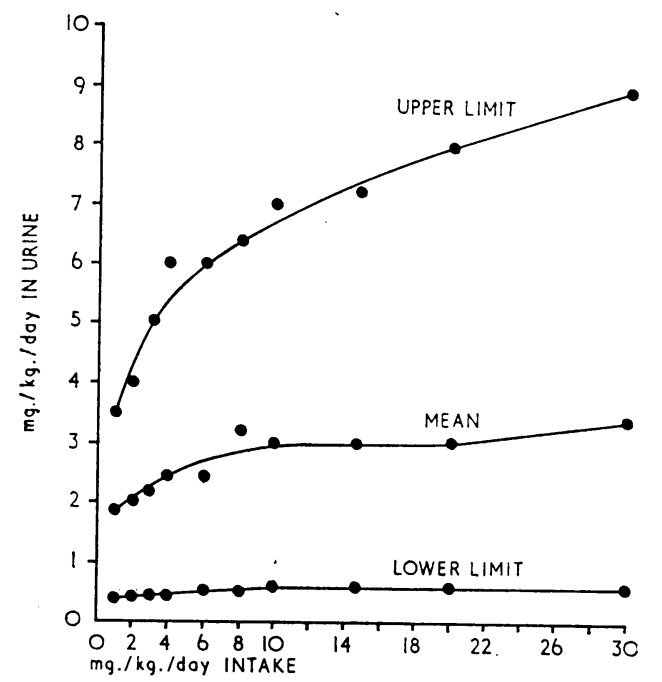

FIG. 5.-Relation between urinary and dietary calcium in normal individuals calculated from the data of Knapp (1947).

calcium of normal subjects is distributed asymmetrically in that there is a "tail" of high values in any normal population, which has been variously estimated at $10-14 \%$ of the total (Hodgkinson and Pyrah, 1958). This is probably not attributable to differences in intake, since it is still apparent when intake is taken into account (Knapp, 1947 ; Watson and Dale, 1966). We have therefore recalculated the data of Knapp (1947) to make them comparable with our own (Fig. 5), and found that the hypercalciuria of her normal individuals is essentially the same as that of our stone-formers. Examination of the "upper limit" in Fig. 5 shows that Knapp's series of 606 subjects must have included a small proportion of "hypercalciuric" individuals in whom the slope of urinary on dietary calcium was much steeper than in the majority. This " hypercalciuria " is not apparent at very low calcium intakes where the distribution of urinary calcium is apparently normal, but as the intake is raised the upper limit rises steeply in much the same way as in our hypercalciuric stone-formers shown in Figs. 1 and 2. We take this to mean that the basis of "idiopathic" hypercalciuria in stone-forming individuals is probably the same as that in normal controls-that is, absorptive in origin. This implies that idiopathic stone-formers are largely drawn from that segment of the population in whom absorption, and therefore urinary excretion of calcium, is above the average.

\section{Summary}

Urinary calcium was determined at two known levels of intake in 31 male and 21 female idiopathic stone-formers, and the results are compared with 13 males and 21 females with no history of stone. In addition, comparable data collected from the literature on 31 normal male adults are included.

At low-calcium intakes there was little difference in the urinary calcium excretion of stone-forming and non-stoneforming individuals, but as the intake was raised the urinary calcium rose more steeply in the stone-formers than in the controls. "Hypercalciuria" was therefore detectable only at moderately high calcium intakes, the characteristic feature of this syndrome being a steep slope of urinary on dietary calcium. This relation of urinary to dietary calcium is similar to that reported by Knapp (1947) in a small proportion of normal individuals.

It is concluded that "hypercalciuria" can only be defined in relation to calcium intake ; that "idiopathic hypercalciuria" is generally attributable to an increased calcium absorption; and that the hypercalciuria of idiopathic stone disease is probably of the same nature as that seen in a small proportion of normal individuals.

\section{REFERENCES}

Albright, F., Henneman, P., Benedict, P. H., and Forbes, A. P. (1953). F. clin. Endocr., 13, 860.

Caniggia, A., Gennari, C., and Cesari, L. (1965). Brit. med. 7., 1, 427. Clarkson, E. M., McDonald, S. J., and de Wardener, H.' E. (1966). Clin. Sci., 30, 425.

Dent, C. E., and Watson, L. (1965). Brit. med. 7., 2, 449.

Dent, C. E., and Watson, L. (1965), Brit. med. F., 2, 449, 143.

Edwards, N. A., and Hodgkinson, A. (1965), Clin. Sci,

Gill, J. R., and Bartter, F. C. (1961). Э. clin. Invest., 40, 716.

Harrison, A. R. (1959). Brit. ¥. Urol., 31, 398.

Henneman, P. H., Benedict, P. H., Forbes, A. P., and Dudley, H. R (1958). New Engl. Э. Med., 259, 802.

Hodgkinson, A. (1961). Proc. Ass. clin. Biochem., 1, 52.

acks and Pyrah, L. N. (1958). Brit. F. Surg., 46, 10. Endocr., 19, 658

Knapp, E. L. (1947). \%. clin. Invest., 26, 182.

Knapp, E. L. (1947). 3. clin. Invest., 26, 182. F. R. (1961). \%. Urol. (Baltimore), 86, 17 .

Malm, O. J. (1958). Scand. 7. clin. Lab. Invest., 10, Suppl. No. 36.

Nordin, B. E. C., and Smith, D. A. (1965). Diagnostic Procedures in Disorders of Calcium Metabolism., London.

Parfitt, A. M., Higgins, B. A., Nassim, J. R., Collins, J. A., and Flilb, A. (1964). Clin. Sci., 27, 463.

Steggerda, F. R., and Mitchell, H. H. (1941). F. Nutr., 21, 577.

Watson, L., and Dale, N. E. (1966). Clin. Sci., 31, 77. 